\title{
DA UTILIZAÇÃO DO NOME SOCIAL DO MENOR TRANSGÊNERO NA ESCOLA COMO MANIFESTAÇÃO DE UM SISTEMA
}

EDUCACIONAL INCLUSIVO

\section{THE USE OF THE SOCIAL NAME OF THE MINOR TRANSGENDER IN SCHOOL AS A MANIFESTATION OF AN INCLUSIVE EDUCATIONAL SYSTEM}

Simone Alvarez Lima ${ }^{1}$

RESUMO: A transgenia vem deixando de ser um tabu para se tornar uma realidade amparada pelo Estado Democrático de Direito. O primeiro aspecto identificador de uma pessoa é o nome, o qual deve ser coerente com a imagem e isso assume maior importância quando se trata de criança e adolescente, grupo, costumeiramente, vítima de bullying nas escolas. A Resolução $n^{\circ} 1$ de janeiro de 2018 do MEC, trouce um avanço ao permitir a matrícula com o nome social, entretanto, a exigência da anuência do representante legal fez com que crianças e adolescentes que não recebem apoio familiar permanecessem desprotegidos e obrigados ao chamamento pelo nome civil.

Palavras-chave: Crianças. Adolescentes. Transgenia. Nome social. Direito à educação.

ABSTRACT: Transgender is no longer a taboo to become a reality underpinned by the Democratic Rule of Law. The first identifying aspect of a person is the name, which must be consistent with the image and this assumes greater importance when it comes to child and adolescent group, usually the victim of bullying at school. Resolution No. 1 of january 2018 of the MEC brought an advanced for allowing kids and teenagers being egistrated with the social name, however, the requirement of consent of the legal representative made those who do not receive family support remain unprotected and forced to be called for their civil name

Keywords: Children. Teenagers. Transgenia. Social name. Right to education.

\footnotetext{
${ }^{1}$ Doutora em Direitos Fundamentais e Novos Direitos pela Universidade Estácio de Sá. Especialista em Direito Constitucional pela Universidade Cândido Mendes. Professora Universitária da Universidade Estácio de Sá das disciplinas Direito Internacional, Direito Constitucional e Fundamentos Antropológicos. Rio de Janeiro /RJ. E-mail: sissyalvarez22@yahoo.com.br. ORCID: https://orcid.org/0000-0002-8431-8205.
} 
Sumário: 1. Introdução. 2. O respeito à dignidade humana oriundo do uso do nome social. 3. Inclusão educacional de transgêneros e travestis na Constituição Federal de 1988. 4. Resolução no 1 , de 19 de janeiro de 2018 do MEC. 5. Das crianças e adolescentes desamparados pela Resolução $\mathrm{n}^{\circ}$ 1/2018 do MEC e o papel das instituições. 6. Conclusão. 7. Referências.

\section{INTRODUÇÃO}

O presente artigo tem como objetivo abordar e ressaltar a importância da Resolução $n^{\circ}$ 1, de 19 de janeiro de 2018 do Ministério da Educação, que possibilitou ao menor transexual ou travesti ser matriculado com o seu nome social. No caso de menores de 18 anos, é necessária a representação/assistência dos pais ou representante legal para que o menor transgênero seja chamado pelo nome condizente com a sua imagem.

O primeiro item é destinado a mostrar como o nome social do transexual e travesti se relaciona com princípios constitucionais como a dignidade da pessoa humana e demais direitos fundamentais.

No segundo item, apresenta-se a Resolução no 1 , de 19 de janeiro de 2018, desde o seu histórico até os seus artigos e o avanço que trouxe em relação à situação anterior, ou seja, quando crianças e adolescentes precisavam passar pelo constrangimento de ser chamados pelos seus nomes civis, mesmo apresentando uma outra aparência, o que, normalmente, levava à evasão escolar.

Por fim, o último item é destinado a criticar a necessidade de anuência dos representantes legais e apresenta algumas possiblidades quando a escola se encontra diante do dilema: a criança pede para ser chamada pelo seu nome social, entretanto, os pais discordam desta conduta. Mostra-se como o Conselho Tutelar e o Ministério Público podem ajudar neste tipo de situação.

Trata-se de uma pesquisa realizada pelo método hipotético-dedutivo, pois elege uma hipótese a fim de solucionar um problema, ou seja, a possibilidade da dispensa da anuência dos pais para que as crianças sejam chamadas pelo nome social por ostentarem a condição de pessoas em formação, de um grupo vulnerável, e que, apesar do avanço trazido pela Resolução nº 1/2018 do MEC, ainda é necessário ampliar a proteção para 
os que estão ainda mais vulneráveis por não encontrarem amparo dentro de casa e este artigo traz argumentos que podem ser utilizados por aqueles que querem ter seus direitos fundamentais respeitados, tendo em vista que para usufruí-los não há idade mínima.

\section{O RESPEITO À DIGNIDADE HUMANA ORIUNDO DO USO DO NOME SOCIAL}

A Constituição Federal de 1988 inseriu, em seu art. 1º, III, a dignidade da pessoa humana no rol dos fundamentos do Estado Democrático de Direito. De acordo com Novais (2004, p. 52), quando a dignidade humana é elevada à condição de princípio estruturante e fundamento do Estado de Democrático de Direito, é o Estado que passa a servir como instrumento para a garantia e promoção da dignidade das pessoas individual e coletivamente consideradas e, atualmente, dentre os assuntos que está dentro do amplo conceito de dignidade, está a questão de gênero.

Nas palavras de Gross (2017, p. 40), “a efetividade dos direitos à integridade física, à saúde, à educação, ao desenvolvimento saudável, entre outros, são facetas formadoras do conceito de dignidade da pessoa humana", da qual também é titular a pessoa transgênero.

Jucá, Silva e Cunha Junior (2017, p. 182) ressaltam a importância de debates referentes às questões de gênero, pois compreender "as nuances sobre identidade de gênero, sexo e sexualidade, suas diferenças e mecanismos de percepção, evitaria inúmeras opressões que essa população marginalizada sofre diariamente nas ruas, no trabalho, no âmbito familiar", e, claro, também, na escola.

Para Jucá, Silva e Cunha Junior (2017, p. 187), transexualidade "é uma quebra do binarismo homem-mulher, na qual muitas pessoas não coadunam com as regras de gênero impostas num ideário de endeusamento do biológico e decidem assumir uma identidade de gênero diferente da que lhe foi atribuída ao nascer." Bento explica o sofrimento e a angústia que o transexual vive, ressaltando que: 


\begin{abstract}
A fuga do cárcere dos corpos-sexuados é marcado por dores, conflitos e medos. As dúvidas "por que eu não gosto dessas roupas? Por que odeio tudo o que é de menina? Por que tenho este corpo?" levam os sujeitos que vivem em conflito com suas dores, a sentir-se uma aberração, uma coisa impossível de existir. Quais os mecanismos sociais que produzem nas subjetividades essa sensação de anormalidade? Como as instituições operam para serem eficazes no seu intento de naturalizar os gêneros? (BENTO, 2011, p. 551)
\end{abstract}

A dignidade humana é um elemento que confere sentido e legitimidade a uma ordem constitucional, o que, de acordo com Sarlet implica um dever de interpretação de toda a ordem jurídica com base neste fundamento.

Com efeito, verifica-se que na sua atuação como limite, a dignidade implica não apenas que a pessoa não pode ser reduzida à condição de mero objeto da ação própria e de terceiros, mas também o fato de que a dignidade constitui o fundamento e o conteúdo de direitos fundamentais contra atos que a violem ou a exponham a ameaças e riscos, no sentido de posições subjetivas que têm por objeto a não intervenção por parte do Estado e de terceiros no âmbito de proteção da dignidade (SARLET, 2018, p. 271).

A proteção aos direitos fundamentais não é dever apenas do Estado, mas, também, dos particulares, tais como as instituições de ensino. No Brasil, prevalece a teoria da eficácia direta e imediata dos direitos fundamentais na esfera privada, logo, não caberia a uma escola rechaçar os valores constitucionais sob o argumento de que a Constituição Federal é dirigida somente contra o Estado. Conforme a explicação de Sarmento (2004, p. 245), direitos fundamentais podem ser invocados nas relações privadas, independentemente de mediação por parte do legislador, e "a opção constitucional pelo Estado Social importaria no reconhecimento desta realidade, tendo como consequência a extensão dos direitos às relações entre particulares." Assim, qualquer escola, pública ou privada, precisa garantir às crianças e adolescentes a tutela dos seus direitos fundamentais. Ainda de acordo com o autor:

No ordenamento brasileiro, que tem em seu cimo uma Constituição fortemente voltada para o social, não é possível conceber tais direitos como meros limites ao poder do Estado em favor da liberdade individual. A Constituição e os direitos fundamentais que ela consagra não se dirigem apenas aos governantes, mas a todos, que têm de conformar seu 
comportamento aos ditames da lei Maior. Isto porque a Constituição de 1988 não é apenas a Lei Fundamental do Estado brasileiro. Trata-se, na verdade, da Lei Fundamental do Estado e da sociedade, porque contém os principais valores e diretrizes para a conformação da vida social no país (SARMENTO, 2004, p. 277).

A ordem jurídica privada, tal como o é o Direito Civil e, de certa forma, o Direito do Consumidor, esferas que se interceptam no ambiente escolar, não estão desvencilhados da Constituição Federal, que irradia seus valores para todo o ordenamento jurídico, levando-lhes legitimidade e, por esse motivo, a interpretação da Constituição Federal não deve ser feita de modo estático, mas, sim, evolutivamente, e, nos casos que envolvem pessoas transgênero, deve ser interpretada sob o enfoque da evolução dos direitos da personalidade e fundamentais das crianças e dos adolescentes.

Connell (2016, p. 141) verificou que, antigamente, o foco dos manuais sobre adolescência eram as mudanças físicas da puberdade, especialmente a menarca e o desenvolvimento dos testículos. Entretanto, "as mudanças físicas são importantes, mas elas não determinam absolutamente como se experimenta a adolescência." Neste sentido, Dias (2016, p. 237) explica que até a mudança física no corpo do adolescente transexual gera sofrimento oriundo da vontade de aniquilar os seus órgãos genitais.

Além dos órgãos genitais, o nome civil é fonte de sofrimento ao transexual, devido ao fato de, como ele não é condizente com a imagem que a pessoa carrega, ela passa a ser objeto da curiosidade alheia. Nas palavras de Gonçalves (2013, p. 148), o nome "integra a personalidade, individualiza a pessoa não só durante a sua vida como também após a sua morte e indica a procedência familiar. É uma etiqueta colocada sobre cada um de nós; ele dá a chave da pessoa inteira." É pelo nome que somos conhecidos em nossa própria história e é por meio dele que pessoas que não puderam conhecer alguém em vida saberão o que aquele indivíduo viveu e propagarão a história deste.

Com este raciocínio, entende-se que o nome tem uma importância além do registro perante o Estado, mas também de dar reconhecimento social a uma pessoa e isso toma maior relevância quando se trata de transexual, uma vez que há dissonância entre o nome civil e o nome social que a pessoa decidiu adotar a fim de se proteger da 
curiosidade alheia, de perguntas e da invasão de privacidade. Nas palavras de Dias (2016, p. 241), “o novo paradigma do Direito estabelece o nome como um elemento identificador real, não meramente formal, adormecido e odiado em uma folha de registro civil."

Dias (2016, p. 54) conceitua nome social como "a designação pela qual travestis e transexuais se identificam e são socialmente reconhecidos, sem que tenham precedido à alteração da identidade civil". O nome social é o prenome pelo qual as pessoas transexuais se reconhecem e que está em sintonia com a identidade sexual publicamente assumida.

De acordo com o Procedimento Administrativo oriundo do Ministério Público do Estado do Paraná MPPR-0046.13.012971-4, a Constituição Federal de 1988, mesmo que não explicitamente, reforça o direito à inclusão do nome social segundo a identidade de gênero, através de princípios com força normativa, tais como art. $1^{\circ}$, III (dignidade da pessoa humana); art. $3^{\circ}$, I (construção de uma sociedade livre, justa e solidária), III (erradicação da pobreza e da marginalização e redução das desigualdades socias regionais) e IV (promoção do bem de todos, sem preconceitos de origem, raça, sexo, cor, idade e quaisquer outras formas de discriminação), art. $5^{\circ}, \mathrm{X}$ (intimidade, vida privada, honra e a imagem), art. 205 (educação) e art. 206 (princípios da educação).

O nome social já é garantido em diversas situações. A Ação Direta de Inconstitucionalidade $\mathrm{n}^{\circ} 4.275 / 2009$ teve como objeto o reconhecimento da retificação do registro civil por via administrativa, sem necessidade de comprovar patologia ou modificação corporal. No âmbito da Administração Pública Federal, é assegurado o direito ao nome social pelo Decreto Presidencial no 8.727, de 28 de abril de 2016; no Sistema Único de Saúde, a utilização do nome social está assegurada na Portaria $n^{\circ}$ 1.820/2009 e a Receita Federal expediu Instrução Normativa n ${ }^{\circ}$ 1.718, de 18 de julho de 2017, que autoriza a inclusão do nome social no CPF do contribuinte transexual ou travesti, assim como as Resoluções da Ordem dos Advogados do Brasil ( $\mathrm{n}^{\circ}$ 5/2016) e do Conselho Federal de Psicologia ( $\left.\mathrm{n}^{\circ} 10 / 2018\right)$ que buscaram primar pela dignidade da pessoa humana e por uma sociedade inclusiva e livre de preconceitos. 
Não se trata de nome artístico ou apelido, mas um nome que assume tamanha relevância que, socialmente, substitui o nome de registro, o qual, muitas vezes é ignorado por diversas pessoas. De acordo com a professora Luma Nogueira de Andrade, “o nome ser negado significa o não acesso aos espaços educacionais. Portanto, se trata de um direito fundamental que é a educação. Tenho que ter o mesmo acesso à escola como todas as pessoas neste país, considerando as minhas singularidades." (SINDMETAL- PE, 2018)

Incluir um aluno não é apenas lhe permitir o acesso à matrícula em uma escola, mas despindo ou ignorando as diferenças, mas, sim, aceitá-las. Pessoas transexuais são incluídas quando se respeita à sua identificação, que se traduz no nome da pessoa. Apenas aceitando o nome social, a criança ou adolescente não será constrangido em situação que, para um transgênero, não é simples, como ser chamado para pegar uma prova, ao responder uma chamada e ao ter que assinar algum documento escolar.

\section{INCLUSÃO EDUCACIONAL DE TRANSGÊNEROS E TRAVESTIS NA CONSTITUIÇÃO FEDERAL DE 1988}

Para Bowles (2016, p. 288), as escolas existem para preparar as crianças para a fase adulta, mas, a partir dos anos 60, o termo "currículo oculto" alegava que existem elementos de socialização nas escolas que não são parte do currículo educacional formal. $\mathrm{O}$ art. 205 da Constituição Federal estabelece que "a educação, direito de todos e dever do Estado e da família, será promovida e incentivada com a colaboração da sociedade".

O conceito de educação é descrito por Mello, in fine:

É mais compreensivo e abrangente do que o da mera instrução. A educação objetiva propiciar a formação necessária ao desenvolvimento das aptidões, das potencialidades e da personalidade do educando. O processo educacional tem por meta: a) qualificar o educando para o trabalho; e b) prepará-lo para o exercício consciente da cidadania. $\mathrm{O}$ acesso à educação é uma das formas de realização concreta do ideal democrático. (MELLO FILHO, 1986, p. 533) 
O art. 205 traz um modelo inclusivo de educação para o Brasil. Montoan (2005) ensina que inclusão escolar se relaciona com "a capacidade individual das pessoas de entender, reconhecer e saber conviver com o outro, o diferente, e a inclusão escolar tem o poder de acolher a diversidade e de fazer a interação desses alunos de forma menos complexa." Complementando Montoan, Drago (2013) ressalta que "a inclusão requer a quebra cristalizações educacionais que fazem com que tantas pessoas sejam deixadas à margem do conhecimento escolar por apresentarem características que destoam daquilo que, convencionalmente, se tem como normal.".

O art. 206, I da Constituição Federal preceitua a igualdade de condições para o acesso e permanência na escola, impondo que não basta que o aluno seja matriculado ou que sejam ofertadas vagas nas escolas, mas que a Constituição e demais legislações referentes à educação devem coibir qualquer ato que venha a afastar a criança e o adolescente da escola.

Conforme os ditames do art. 214 da Constituição Federal, a lei estabelecerá o plano nacional de educação com o objetivo de definir objetivos, metas e estratégias de implementação para assegurar a manutenção e desenvolvimento do ensino por meio de ações integradas que conduzam a erradicação do analfabetismo, universalização do atendimento escolar, melhoria da qualidade de ensino; formação para o trabalho; promoção humanística, científica e tecnológica do país.

Perceba que esses artigos que tratam da educação, em conjunto com os artigos que mencionam os princípios e objetivos da República Federativa do Brasil destacam a inclusão e educação para todos a fim de trazer melhores condições de empregabilidade no futuro.

Em nenhum momento, a Constituição Brasileira excluiu travestis e transexuais de receber um ensino de qualidade, entretanto, não dá para garantir a igualdade formal e ignorar a realidade social que afasta aqueles que são atingidos pela crueldade do bullying nos estabelecimentos de ensino. Assim, ainda que a Constituição lhes permita o ensino, a proibição do uso do nome social impede o seu acesso e a permanência na escola tamanho o desconforto que o nome civil pode causar. 
O problema piora quando a criança e o adolescente não têm o apoio dos pais e, ainda que os responsáveis saibam que ele pertença a um gênero diferente, preferem ignorar a condição do filho/representado e matrícula a criança com seu nome civil, situação esta que pode ser evitada pela Resolução $n^{\circ} 1$ do Ministério da Educação e da Cultura, objeto do próximo item.

No plano infraconstitucional, há a Lei nº 9.394, de 20 de dezembro de 1996, que estabelece as bases da educação nacional, que se desenvolve, predominantemente, por meio de ensino, em instituições próprias. De acordo com o art. $1^{\circ}, \S 2^{\circ}$, desta lei, "a educação escolar deverá vincular-se ao mundo do trabalho e à prática social."

Assim, a educação deve fornecer as condições para que qualquer ser humano tenha a oportunidade de ser inserido no mercado de trabalho, mas, se a própria escola constrange o transgênero e o travesti, insistindo em chamá-lo pelo nome civil, é de se indagar como essas pessoas podem se preparar para o mercado de trabalho se preferem faltar às aulas do que serem constrangidas.

A partir do título II, a Lei no 9.394/96 enumera os princípios e fins da educação nacional, os quais se coadunam com os ditames da Constituição Federal, tais como: igualdade de condições para o acesso e permanência na escola; pluralismo de ideias e de concepções pedagógicas.

A Lei $n^{\circ} 9.394 / 96$ versa a respeito da liberdade e do apreço à tolerância, os quais são efetivados quando a criança e o adolescente transexual podem se apresentar com um nome condizente com a sua aparência e não ser vítima de chacota ou curiosidade dos demais colegas que, por também serem pessoas em formação, não têm, ainda, consciência do quanto palavras injuriosas ou debochadas podem magoar.

Dentre os métodos de interpretação da Constituição Federal é o conhecido como científico-espiritual, o qual enxerga a Constituição como um "sistema cultural e de valores de um povo, cabendo à interpretação aproximar-se desses valores subjacentes à Constituição. Esses valores estão sujeitos a flutuações, tornando a interpretação da Constituição elástica e flexível." (MENDES; BRANCO, 2018, p. 90) Desta forma, a Constituição e todos os seus artigos referentes à educação e não-discriminação devem 
ser interpretados de modo a assegurar que travestis ou transexuais sejam respeitados no âmbito escolar.

A Constituição Federal também deve ser interpretada de forma una e o art. 227 não deve ser lido isoladamente, mas em reforço ao art. $1^{\circ}$, III (a dignidade da pessoa humana); art. $3^{\circ}$, I (construção de uma sociedade livre, justa e solidária); art. $3^{\circ}$, IV (promoção do bem de todos, sem preconceitos de origem, raça, sexo, cor e qualquer outras formas de discriminação). De acordo com o art 227:

Art. 227. É dever da família, da sociedade e do Estado assegurar à criança, ao adolescente e ao jovem, com absoluta prioridade, o direito à vida, à saúde, à alimentação, à educação, ao lazer, à profissionalização, à cultura, à dignidade, ao respeito, à liberdade e à convivência familiar e comunitária, além de coloca-los a salvo de toda forma de negligência, discriminação, exploração, violência, crueldade e opressão.

Mendes e Branco (2018, p. 95) ensinam que o princípio da unicidade constitucional auxilia a que argumentos jurídicos se desenvolvam em um contexto de maior racionalidade, favorecendo um controle sobre o processo de concretização das normas previstas na Constituição Federal.

O artigo 227, junto com o Estatuto da Criança e do Adolescente, busca dar efetividade ao princípio da proteção integral da criança, que, nas palavras de Lôbo (2010, p. 45), "não é uma recomendação ética, mas diretriz determinante nas relações da criança e do adolescente com seus pais, com sua família, com a sociedade e com o Estado.” No mesmo diapasão, Dias reforça a necessidade de proteção especial às crianças e aos adolescentes:

A maior vulnerabilidade e fragilidade dos cidadãos até os 18 anos, como
pessoas em desenvolvimento, os faz destinatários de um tratamento especial.
Daí ser consagrado a crianças, adolescentes e jovens, com prioridade absoluta,
direito à vida, à saúde, à alimentação, à educação, ao lazer, à
profissionalização, à cultura, à dignidade, ao respeito, à liberdade e à
convivência familiar e comunitária. (DIAS, 2017, p. 57) 
Martins (2018), em reportagem para o site Agência Brasil, explanou a respeito da situação vivenciada pela estudante Lara, de 13 anos de idade, no Ceará. Como ela assumiu que se reconhecia como uma mulher, foi convidada a sair da escola. Durante o período escolar, a jovem tinha que usar o seu nome civil masculino, em todos os registros escolares, como provas e boletins. "Até o direito de ter o nome social garantido na carteirinha de estudante, que era assegurado pelo órgão emissor do documento, foi inviabilizado pela escola, que não confirmou a matrícula da estudante ao órgão."

A história de Lara foi apenas uma dentre várias outras de preconceito por transgenia, que a Constituição Federal e a legislação infraconstitucional, em matéria de educação, não foram capazes de coibir, mas, a partir de 2008, surgiram discussões no âmbito das escolas, a respeito dos transgêneros crianças e adolescentes, que levaram ao advento da Resolução nº 1 , de 19 de janeiro de 2018 do MEC, que levou à diminuição de condutas discriminatórias e de evasão escolar devido à não utilização do nome social.

\section{RESOLUÇÃO No 1, DE 19 DE JANEIRO DE 2018 DO MEC}

Santos (2015) aponta que, desde 2008, após a realização da I Conferência Nacional LGBT, o movimento social de lésbicas, gays, bissexuais, travestis e transexuais assumiu a demanda pela utilização do nome social nos registros escolares de travestis e transexuais. A Conferência destacou uma narrativa comum do movimento social, "que consiste em dizer que não tiveram as mesmas condições de frequentar a escola e adquirir a formação mínima exigida pelo mercado de trabalho formal. Consequentemente, essa situação de exclusão escolar atribui a esses indivíduos um único tipo de inserção, isto é, a prostituição."

Em 2008, a Secretaria de Educação do Estado do Pará, por meio da Portaria n ${ }^{\circ}$ 016/2008-GS estabeleceu que, a partir de 02 de janeiro de 2009, todas as escolas da rede pública paraense passariam a registrar, no ato da matrícula dos alunos, o prenome social de travestis e transexuais, o que serviu de exemplo para diversos estados brasileiros. 
O direito à educação vai além de fornecer ensino fundamental gratuito, pois não basta acessar a escola, é necessário que o Estado dê as condições para que a pessoa permaneça no estabelecimento de ensino, preocupação mencionada na Resolução $n^{\circ} 1$, de 19 de janeiro de 2018, que considerou que: "a legislação nacional ampara o entendimento de que estudantes menores de 18 anos são portadores de direito, e que a evasão escolar constitui grave atentado contra o direito à educação."

A escola, de acordo com os considerandos da Resolução em estudo, deve primar pelo acesso e permanência de qualquer tipo de aluno e que este local "deve ser um ambiente acolhedor e seguro, onde o estudante encontre assistência e orientação. O objetivo é que todos possam sentir prazer em estar na escola." Ora, a partir do momento em que a criança e o adolescente ficam protegidos de brincadeiras maldosas porque seu nome não condiz com sua imagem, a escola deixa de ser um local de tortura mental para se tornar propício ao aprendizado.

A Resolução $n^{\circ} 1$ ainda considerou os princípios que norteiam a legislação educacional no país, que asseguram o respeito à diversidade, à proteção de crianças e adolescentes e ao inalienável respeito à dignidade humana; e que a diversidade sexual e o respeito à identidade de gênero são congruentes com os valores universais da contemporaneidade democrática.

Pelo menos, no âmbito educacional já podiam, antes da mencionada Resolução, ser verificados esforços para neutralizar os problemas oriundos das diferentes questões de gênero e transgenia. Estados brasileiros, tais como Pará, Maranhão, Paraná, Alagoas, Rio Grande do Sul, Mato Grosso, Santa Catarina, Goiás, São Paulo, Bahia, Tocantins e Distrito Federal foram pioneiros em regulamentar a utilização do nome social travestis em escolas, entretanto faltava uma regulamentação em âmbito nacional, pois, até 2018, ficava a cargo da escola lidar com as diferenças da presença transexual em suas salas de aula.

Pessoas que fabricam seus corpos e identidades de gênero, de modo diferente daquele atribuído a partir da genitália ao nascer, e que ousam adentrar os espaços e tempos escolares como estudantes, em geral, causam 
estranhamentos, incômodos, curiosidades e mexericos, perturbando a ordem da escola. Corpos e subjetividades fabricadas a partir da subversão das rígidas normas de gênero da sociedade ocidental contemporânea circulando pela escola. Diante dessa situação, por muito tempo impensável, as personagens habituais desse palco, que compõem a denominada comunidade escolar, se perguntam: como é possível a presença desses corpos na escola? (SANTOS, 2015).

A Resolução nº 1, de 19 de janeiro de 2018, do Ministério da Educação trouxe um avanço na proteção de crianças e adolescentes contra bullying na escola e na promoção de sua identidade de gênero. Esta Resolução foi aprovada, de forma unânime, pelo Conselho Nacional de Educação por ser uma reivindicação de representantes de grupos LGBTI e que ressalta que o uso do nome social já era permitido nas inscrições do ENEM (Exame Nacional do Ensino Médio).

Trata-se de uma pequena Resolução, composta por apenas 5 artigos, mas que soluciona situações vexatórias e afrontosas à dignidade da pessoa humana de um setor vulnerável, crianças e adolescentes em idade escolar. A partir desta Resolução, o menor de idade poderá solicitar o direito de ser chamado pelo nome social, por via de seus representantes legais.

Apesar da sociedade estar aprendendo a lidar com as diferenças, ainda há homofobia contra as pessoas que fogem do padrão heteronormativo e a Resolução nº1/2018 do MEC foi uma demonstração de que o Brasil está sensível às discriminações que sofrem os estudantes LGBTI, nas escolas brasileiras, em função de suas identidades de gênero e que entendeu que a utilização do nome social em sala de aula trará um impacto positivo na vida dessas pessoas.

Além disso, dentro dos motivos que foram expostos nas considerações da Resolução em estudo, o Ministério da Educação e da Cultura reforçou a responsabilidade das instituições educacionais na educação e na formação dos estudantes, com respeito aos valores humanos que levam a uma sociedade fraterna e harmoniosa. Assim, a Resolução $n^{\circ} 1 / 2018$ busca garantir o respeito à autonomia da vontade e à liberdade individual de se expressar, além de afastar a obrigação da criança e do adolescente a se submeter a uma ordem compulsória sexual e cisnormativa. 
$\mathrm{O}$ art. $1^{\circ}$ estabelece que o sistema de ensino deve assegurar diretrizes e práticas que combatam a discriminação em função de orientação sexual e identidade de gênero de estudantes, professores, gestores, funcionários e respectivos familiares. Não por acaso é que o art. $2^{\circ}$ institui a possibilidade do uso do nome social de travestis e transexuais nos registros escolares da educação básica.

$\mathrm{O}$ art. $2^{\circ}$ resolve as dúvidas de diversos profissionais da educação, tais como: como chamar uma criança que se diz pertencer a outro gênero? Uma vez que os próprios pais matricularam o filho de acordo com o nome social, não há problema em chamar a criança ou adolescente do jeito que ele se sente mais protegido em sua privacidade e dignidade.

Quando o aluno for maior de 18 anos, ele pode solicitar a utilização do nome social, tanto durante a matrícula como em qualquer outro momento, sem necessidade de mediação (art. $3^{\circ}$ ), entretanto, quando for menor de 18 anos, o aluno pode solicitar o uso do nome social, mas desde que por meio de seus representantes legais, em conformidade com o art. 1.690 do Código Civil e Estatuto da Criança e do Adolescente.

No âmbito dos direitos humanos, a Carta de Princípios de Yogykarta sobre a aplicação da legislação internacional de direitos humanos em relação à orientação sexual e identidade de gênero, em seu princípio 16, impõe aos Estados que adotem medidas legislativas, administrativas e de qualquer outra índole necessária para garantir o acesso à educação em igualdade de condições e o trato igualitário de estudantes no sistema educativo, sem discriminação por motivos de orientação sexual ou identidade de gênero.

Apesar do Estatuto da Criança e do Adolescente não contar com a expressão nome social, o art. $3^{\circ}$ dispõe que "a criança e o adolescente gozam de todos os direitos fundamentais inerentes à pessoa humana, sem prejuízo da proteção integral de que trata esta lei, assegurando-lhes, por lei ou por todos meios, todas as oportunidades e facilidades, a fim de lhes facultar o desenvolvimento físico, mental, moral, espiritual e social, em condições de liberdade e de dignidade."

Já o art. $4^{\circ}$ do Estatuto da Criança e do Adolescente dispõe, nos mesmos moldes da Constituição Federal, que é dever da família, da comunidade, da sociedade e do poder 
público assegurar, com absoluta prioridade, a efetivação dos direitos referentes à vida, à saúde, à alimentação, à educação, ao esporte, ao lazer, à profissionalização, à cultura, à dignidade, ao respeito, à liberdade e à convivência familiar e comunitária. Perceba que a legislação específica não diferenciou crianças e adolescentes em razão de sua idade.

Não é possível negar que nem todos os pais lidam bem com o gênero que o filho apresenta diferente do sexo biológico e, por isso, certamente se recusará a matricular o filho com o seu nome social, fazendo questão de utilizar o nome civil, talvez, a fim de convencer à criança de que discussões a respeito de gênero precisam ser ignoradas para salvar o filho de algo que, muitas vezes, nem mesmo o pai ou a mãe sabem.

\section{DAS CRIANÇAS E ADOLESCENTES DESAMPARADOS PELA RESOLUÇÃO No 1/2018 DO MEC E O PAPEL DAS INSTITUIÇÕES}

Certamente, não há apenas um caso em que pai e mãe não aceitam a identidade de gênero do filho e, na esperança de uma adaptação compulsória da criança, matriculam o filho com seu nome civil. Não há apenas uma única criança transgênero nesta situação e, nestes casos, o Ministério Público pode auxiliar.

De acordo com o art. 129, II e III, da Constituição Federal, o Ministério Público tem como função institucional zelar pelo efetivo respeito dos Poderes Públicos e dos serviços de relevância pública, como é o caso da educação, promovendo as medidas necessárias para a sua garantia e promover o inquérito civil e a ação civil pública, para a proteção dos interesses difusos e coletivos. Para esta última mencionada função, o amparo infraconstitucional se encontra no art. $1^{\circ}$, IV, da Lei $n^{\circ} 7.347$, de 24 de julho de 1985, que versa sobre ação civil pública no tocante aos direitos coletivos.

Segundo o art. 208 do Estatuto da Criança e do Adolescente, é considerado interesse coletivo deste grupo o ensino obrigatório, o serviço de assistência social visando à proteção à família, à infância e à adolescência, bem como ao amparo desses. Assim, enseja a atuação constitucional do Ministério Público hipóteses em que crianças e adolescentes se distanciam do ensino obrigatório. 
A atuação do Conselho Tutelar, órgão previsto no art. 131 e seguintes do Estatuto da Criança e do Adolescente, não deve ser descartada, tendo em vista que ele assume "lugar de destaque no campo institucional no que tange aos encaminhamentos de crianças e adolescentes que sofram algum tipo de violação de direitos." Trata-se de um órgão autônomo, não jurisdicional e com a incumbência de zelar pelo cumprimento dos direitos da criança e do adolescente. Dentre as atribuições do Conselho Tutelar está atender e aconselhar os pais ou responsáveis e aplicar-lhes medidas, que no caso de não aceitação da identidade trans do filho, poderia ser o encaminhamento a cursos ou programas de orientação; obrigação de matricular o filho ou pupilo e acompanhar sua frequência e aproveitamento escolar e aplicação de advertência.

Como o Conselho Tutelar não é um órgão jurisdicional, para empregar coercibilidade às suas medidas em caso de descumprimento, conforme o art. 136, deverá representar junto à autoridade judiciária os casos de descumprimento injustificado nas suas deliberações e encaminhar ao Ministério notícia de fato que constitua infração administrativa contra os direitos da criança ou adolescente.

Souza, Teixeira e Silva (2003) explicam que a escola deve comunicar ao Conselho Tutelar os casos de crianças que estão faltando com frequência para que os pais sejam notificados, a fim de a escola descobrir o motivo das faltas. Os autores estimulam que o Conselho seja comunicado sobre as faltas rapidamente a fim de não trazer consequências negativas para o aluno, tais como perder matérias e o ano letivo.

O Conselho Tutelar, segundo o art. 55 cumulado com o 56 do Estatuto da Criança e do Adolescente, impõe aos pais a obrigação de matricular seus filhos em rede regular de ensino e aos dirigentes de estabelecimentos de ensino fundamental (onde se encontram as crianças incapazes civilmente) de comunicar os casos de reiteração de faltas injustificadas e de evasão escolar.

$\mathrm{O}$ art. 70 do mesmo Código explica que é dever de todos prevenir a ocorrência de ameaça ou violação dos direitos da criança e do adolescente e, para tal, União, Estados, Distrito Federal devem atuar de forma articulada na elaboração de políticas 
públicas e na execução de ações que coíbam tratamento degradante. Ao ver da Ordem dos Advogados dos do Brasil:

\begin{abstract}
É dever do Estado assegurar tanto o respeito à identidade de gênero como o livre desenvolvimento da personalidade das crianças e adolescentes trans, garantindo-lhes acesso à educação, sem discriminação. Quando falha a família no seu dever de respeitar a liberdade e dignidade de seus integrantes, cabe ao poder público avocar esse múnus e fazer valer os ditames constitucionais, em especial o princípio máximo do melhor interesse da criança e do adolescente, mesmo que contra a vontade dos genitores ou responsáveis. (CFOAB, 2013).
\end{abstract}

Talvez os pais que não matriculam o filho com seu nome social desconheçam o nível de crueldade de algumas crianças. A Resolução privilegia crianças e adolescentes cujos pais apoiam a identidade de gênero da criança, porém, caso os pais ou os responsáveis legais se recusem a fazer a solicitação de uso do nome social da criança, a escola deverá encaminhar o aluno para a Defensoria Pública.

Suprimir a liberdade da criança cujos pais não permitem a alteração do nome não está de acordo com o princípio constitucional do melhor interesse da criança. Assim, haverá uma ponderação entre algumas questões: direito ao exercício do poder familiar, o melhor interesse da criança, a dignidade humana, a vida privada e a honra. Nas palavras de Jucá, Silva e Cunha Junior (2017, p. 191), desrespeitar tais princípios aos quais têm interesse tais crianças, violaria o Estado Democrático de Direito, "que tem por base a erradicação das violências preconceituosas e a priorizar a defesa de grupos vulneráveis, como a população transexual."

$\mathrm{O}$ art. $3^{\circ}$, I do Código Civil estabelece que os menores de dezesseis anos são absolutamente incapazes de exercer pessoalmente os atos da vida civil e, por isso, precisam ser representados pelos pais. Nesta idade, entende-se necessária a representação pelo fato de que estas são presumivelmente incapazes de distinguir o que lhe é conveniente ou prejudicial, entretanto o art. 12 da Convenção das Nações Unidas sobre os Direitos da Criança traz a estas crianças o direito de serem ouvidas e de participarem da definição das medidas tomadas pelo Poder Público no sentido da 
efetivação de seus direitos fundamentais, como educação, direito à dignidade, colocando-os a salvo de preconceito ou discriminação.

Fiel a este entendimento, não é possível, de um lado, deixar de "ouvir" e considerar a opinião de uma pessoa com idade inferior a 16 anos que demanda a inclusão de seu nome social nos registros escolares, mas também não é razoável promovê-la sem maiores cautelas e/ou sem levar em conta outros fatores que podem lhe trazer prejuízos, caso este venha a ocorrer, especialmente se consideradas sua capacidade reduzida e o fato de se tratar de pessoa ainda em fase de desenvolvimento (o que pode ser motivo de dúvidas quanto ao exercício da sexualidade e a própria definição do gênero). (CAOPEDUC, 2014).

O parecer da Comissão de Diversidade Sexual da OAB alerta que a colisão entre o dever de vigilância dos pais e o direito à intimidade, "acompanhada da vida privada, materializa-se em um espaço pessoal, onde não comporta qualquer interferência externa." Não há em lugar algum da Constituição Federal que estabeleça que a pessoa precisa alcançar uma idade mínima para usufruir de seus direitos fundamentais. A OAB trouxe como precedente a Resolução CEE/CP n ${ }^{\circ}$ 5, de 03 de abril de 2009, do Conselho Estadual de Goiás:

que determina às escolas do sistema educativo, em respeito à cidadania, aos direitos humanos, à diversidade, ao pluralismo, à dignidade humana, incluam o nome social de travestis e transexuais nos registros escolares para garantir o acesso, a permanência e o êxito desses cidadãos no processo de escolarização e de aprendizagem (art. $1^{\circ}$ ). $\mathrm{O} \S 2^{\circ}$ estabelece que o discente travesti ou transexual deve tão somente manifestar, por escrito, seu interesse na utilização do nome social, no ato de sua matrícula ou ao longo do ano letivo, sem mencionar qualquer necessidade de prévia autorização dos pais ou responsáveis.

Dias (2016, p. 314) alerta a necessidade de que os estabelecimentos de ensino devem evitar o bullying no ambiente escolar devido à identidade de gênero do aluno e os professores devem ser capacitados para fornecer uma educação inclusiva. Assim, a Comissão Especial de Diversidade Sexual do Conselho Federal da OAB (2013) concluiu que é absolutamente dispensável a autorização dos pais da criança ou do adolescente que optem por serem chamados pelo nome social em documentos internos da instituição de ensino, "bastando apenas que expresse de forma irrefutável esse desígnio." 
Em 2014, foi aberto o Procedimento Administrativo n ${ }^{\circ}$ MPPR-0046.13.0129714 que sugere que, diante da recusa dos pais, o caso seja encaminhado ao Ministério Público. No parecer emitido, ainda foi sugerido que casos de preconceito ou discriminação por questões de gênero devem ser imediatamente comunicados ao Conselho Tutelar e ao Ministério Público (2014).

\begin{abstract}
Em âmbito escolar, é essencial a atuação do Ministério Público no sentido de garantir a existência e continuidade de políticas públicas de enfrentamento do bullying homofóbico e transfóbico, e de programas gerais de promoção e respeito da diversidade na perspectiva da igualdade de acesso e permanência de todas as crianças na escola. Nesse sentido é o enunciado da COPEDUCGNDH-CNPG (Comissão Permanente de Educação do Grupo Nacional de Direitos Humanos, criado pelo Conselho Nacional de Procuradores Gerais): No 39 (10/2016): "Cabe ao Ministério Público adotar medidas que visem garantir a igualdade efetiva de acesso e permanência na escola por parte de todos e todas, nos termos do artigo 206, I, da Constituição Federal, incluindose no projeto político-pedagógico - PPP e regimento escolar, de todos os níveis de ensino, conteúdos relativos aos direitos humanos, à equidade de gênero, de raça ou etnia, de enfrentamento à homofobia, transfobia e ao problema da violência doméstica e familiar contra a mulher. (MPF, 2017).
\end{abstract}

A Comissão Especial da Diversidade Sexual do Conselho Federal da Ordem dos Advogados do Brasil se manifestou sobre a possibilidade de alunos menores de idade utilizarem o nome social sem necessidade de autorização dos pais ou responsáveis.

A escola, ao acatar o pedido do aluno menor de idade pelo uso do seu nome social, não violaria o poder familiar, eis que o art. 1.634 do Código Civil dispõe que dentre os deveres dos pais está o de dirigir-lhes educação e, de acordo com a Comissão Especial de Diversidade Sexual, quando os pais repudiam a natureza sexual de seus filhos, "de modo que isso lhes crie óbices ou constrangimentos na instituição de ensino que frequentem, por consequência, estão falhando no cumprimento de um dos elementos mais importantes do poder familiar."

Recomenda-se que, se houver solicitação do nome social por parte da criança, primeiro, a escola deve dialogar com o responsável, orientando-os a respeito da importância do nome social para o bem-estar daquela criança.

No parecer diversos pontos foram mencionados como o fato de "engessar uma pessoa em condição não equivalente a sua identidade de gênero é deslocar-se na 
contramão da ideia de justiça, limitando suas realizações e a busca da felicidade; a frequente expulsão de travestis de suas casas e serem alvo de bullying e dificuldade de absorção pelo mercado de trabalho. Muito bem foi expresso no parecer da Comissão que não há necessidade de prévia autorização dos pais ou responsáveis para que o menor de idade adote seu nome social, "até porque, usualmente, eles são os que primeiro rechaçam essa condição do filho.”

A prática exige a concordância dos pais. Por parte das escolas, elas devem, nas reuniões de responsáveis, conscientizar a respeito das consequências do bullying que crianças transgênero sofrem. Uma possível solução para as escolas, quando se percebem diante de uma criança transgênero que pede para ser chamada por um nome condizente com a sua imagem, seria recorrer ao Ministério Público.

No caso de uma eventual ação, não seria a escola pleiteando interesse alheio, pois lhe falta legitimidade para demandar direitos de um aluno, mas, sim, o Ministério Público, na qualidade de substituto processual, tendo em vista o art. 129, II e III, em demanda contra os pais. Complementarmente, de acordo com o art. 176 do Código de Processo Civil, “o Ministério Público atuará na defesa da ordem jurídica, do regime democrático e dos interesses e direitos sociais e individuais indisponíveis."

Por fim, vale mencionar que a Resolução $\mathrm{n}^{\circ} 1$ do MEC incorreu em inconstitucionalidade por omissão no sentido horizontal. Essa conclusão não é uma verdade absoluta, mas algo a ser refletido. Até que ponto uma criança vulnerável por ser transgênero, que não conta com o apoio dos responsáveis, precisa sofrer para que sua voz seja ouvida na proteção de seu nome social, um direito de personalidade que tem como característica a intransmissibilidade.

No caso de inconstitucionalidade por omissão horizontal, não cabe retirar a Resolução do ordenamento jurídico, mas, mantê-la, entretanto com o resultado de estender a proteção aos direitos fundamentais de todas as crianças e adolescentes, inclusive, daquelas que não recebem apoio dos pais ou responsáveis para a utilização do nome social. 
Caberia a Procuradoria Geral da Justiça, por meio da Ação de Descumprimento de Preceito Fundamental (ADPF), eliminar a necessidade de autorização dos pais ou responsáveis para garantir que, pelo menos na chamada, de ser solicitada e na hora de assinar a prova, tais crianças possam usar o nome condizente com a sua imagem. A desautorização dos pais que leva à obrigação da criança de aceitar um nome incondizente com o seu gênero e que pode acarretar sua evasão escolar ou em bullying corresponde ao descumprimento de fornecimento de educação, um dos deveres oriundos do poder familiar.

\section{CONCLUSÃO}

É possível concluir que a Resolução nº 1, de 19 de janeiro de 2018, do Ministério da Educação e da Cultura, trouxe um avanço para proteger a dignidade humana de grupos em situação de vulnerabilidade reforçada: crianças e adolescentes transexuais ou travestis, ao permitir a adoção do nome social, no lugar do nome civil, na hora de serem matriculados na escola, um ambiente, muitas vezes, hostil e repleta de pessoas que desconhecem a Constituição Federal e seu princípios, tais como dignidade da pessoa humana, igualdade, pluralismo.

A educação é um direito de todos e não basta garantir a matrícula da pessoa na escola, é necessário que sejam criadas as condições para que a criança e o adolescente queiram permanecer nela e, para isso, as peculiaridades de cada uma devem ser respeitadas e, no caso de crianças e adolescente transgênero, o chamamento pelo nome social é o primeiro passo para que esta criança se sinta confortável. Assim, seus direitos fundamentais ficam resguardados, tendo em vista que seu boletim, seu nome na chamada, sua assinatura na prova, ao ser coerente com sua identidade de gênero evitaria a ingerência alheia em sua intimidade, vida privada e honra.

A escola é um ambiente repleto de pessoas cujo caráter está em formação, daí que o bullying é uma prática, apesar de abominável, frequente, pois estão aprendendo o que é certo e o que é errado e o transgênero e o travesti são vítimas potenciais disso, 
pois ostentam uma imagem incondizente com o seu nome e a Resolução n ${ }^{\circ}$ 1/ 2018 do MEC procurou amparar parte dessas pessoas, mas não a sua totalidade, tendo em vista o requisito de, no caso de menor de idade, da assistência do representante legal para que a matrícula seja feita com base no nome social.

Aquele menor que não conta com o amparo da família, seja por questões de preconceito, religião ou ignorância, não está protegido pela legislação e diversas discussões surgem, pois tais crianças e adolescentes, de acordo com o códex processual brasileiro, não têm legitimidade ativa para pleitear, pessoalmente, seus direitos, entretanto, direitos fundamentais e direitos da personalidade são irrenunciáveis e intransmissíveis e a própria Comissão de Diversidade Sexual da OAB entendeu que essa exigência deveria ser retirada. Os pais ou representantes que preferem ver seu filho humilhado, sofrendo bullying e não indo às aulas para evitar constrangimento, na realidade, não estão cumprindo com o dever oriundo do poder familiar, que é o de prestar educação.

Neste tipo de situação, poderia o Procurador-Geral da República ou o Conselho Federal da Ordem dos Advogados do Brasil, legitimados ativos da Ação de Descumprimento de Preceito Fundamental, ou o Ministério Público, legitimado do Inquérito Civil e da Ação Civil Pública optar por uma dessas vias para amparar o interesse desse grupo com vulnerabilidade reforçada.

A escola não deve impor à criança a utilização de seu nome civil só porque os pais assim o querem, independentemente se a escola é pública ou privada, pois impera no ordenamento jurídico brasileiro a teoria da eficácia imediata dos direitos fundamentais, que ordena o cumprimento desses direitos por parte dos particulares. Desse modo, se a escola perceber o sofrimento da criança ao ter sua intimidade, honra, vida privada, dignidade humana e o direito à educação violados, especialmente no caso de evasão escolar, deve, primeiro, conversar com os responsáveis e caso não os convença, buscar o auxílio do Conselho Tutelar, afinal, a criança apenas não tem capacidade ativa para pleitear pessoalmente seus direitos, entretanto, é titular deles e, se 
se quem deveria ampará-las, não o faz, é necessária a atuação dos órgãos mencionados, pois a criança transgênero é uma realidade que não pode ser ignorada.

\section{REFERÊNCIAS}

BENTO, Berenice. Na escola se aprende que a diferença faz a diferença. Revista Estudos Feministas. Florianópolis, v. 19, n. 2, 2011.

CENTRO DE APOIO OPERACIONAL ÀS PROMOTORIAS DE JUSTIÇA DA CRIANÇA E DO ADOLESCENTE E DA EDUCAÇÃO. Procedimento Administrativo n ${ }^{\circ}$ MPPR 0046.13.012971-4. Disponível em: http://www.crianca.mppr.mp.br/arquivos /File/parecer/parecer_02_2014_pa_mppr_0046_13_012971_4_nome_social_na_esco la.pdf. Acesso em: 04 jan. 2020.

CONNELL, Raewyn. Gênero em termos reais. Trad. Marília Moschkovich. São Paulo: nVersos, 2016.

CONSELHO FEDERAL DA ORDEM DOS ADVOGADOS DO BRASIL. Comissão Especial de Diversidade Sexual. Nota técnica sobre uso do nome social em escolas e universidades.

em: https://www.mprj.mp.br/documents/20184/237640/nota_tecnica_oab_uso_de_nome_s ocial_nas_escolas.pdf. Acesso em: 30 dez. 2019.

COORDENAÇÃO DA EDUCAÇÃO DAS RELAÇÕES DE GÊNERO E DIVERSIDADE SEXUAL - CERGDS. Nome social na escola: travestis e transexuais e $\mathbf{0}$ direito à educação. Disponível em: http://www.educadores.diaadia.pr.gov.br/arquivos/File/dedi/perguntas_res postas_nomesocialnaescola.pdf. Acesso em: 05 jan. 2019.

DIAS, Maria Berenice. Homoafetividade e Direitos LGBTI. 7. ed. São Paulo: Revista dos Tribunais, 2016.

DIAS, Maria Berenice. Manual de Direito das Famílias. 12 ed. São Paulo: Revista dos Tribunais, 2017.

DONEDA, Danilo. Os direitos da personalidade no Novo Código Civil. In: TEPEDINO, Gustavo (Org.) A parte geral do novo Código Civil: estudos na perspectiva civil-constitucional. 3. ed. Rio de Janeiro: Renovar, 2007.

DRAGO, Rogério. Síndromes: conhecer, planejar e incluir. Rio de Janeiro: Wak, 2013. 
GONÇALVES, Carlos Roberto. Direito Civil Brasileiro, v. 1. São Paulo: Saraiva, 2013.

JUCÁ, Roberta Laena Costa; SILVA, Jônatas Isaac Apolônio da; CUNHA JUNIOR, Francisco Gilberto. A institucionalização da transfobia no direito civil brasileiro: uma análise da possibilidade de anulação do casamento da pessoa transexual. Revista Insurgência. Brasília, Ano 3, v. 3, n. 1, 2017.

LÔBO, Paulo. Direito Civil: famílias. 4 ed. São Paulo: Saraiva, 2010.

MELlO FILHO, José Celso. Constituição Federal Anotada. 2. ed. São Paulo: Malheiros, 1986.

MENDES, Gilmar Ferreira; BRANCO, Paulo Gustavo Gonet. Curso de Direito Constitucional. 13. Ed. São Paulo: Saraiva, 2018.

MINISTÉRIO DA EDUCAÇÃO E DA CULTURA (MEC). Resolução no $\mathbf{1}$, de 19 de janeiro de 2018. Disponível em: http://portal.mec.gov.br/index.p hp?option=com docman\&view=download\&alias=81001-rcp001-18-pdf\&category_slug=janeiro-2018pdf\&Itemid=30192. Acesso em: 22 dez. 2019.

MINISTÉRIO PÚBLICO FEDERAL (MPF). O Ministério Público e a Igualdade de Direitos para LGBTI. 2 ed. Brasília: MPF, 2017.

MANTOAN, Maria Teresa Eglér. Inclusão é o Privilégio de Conviver com as Diferenças. Nova Escola. Maio, 2005.

NOVAIS, Jorge Reis. Os princípios constitucionais estruturantes da República portuguesa. Coimbra: Coimbra, 2004.

SARLET, Ingo Wolfgang; MARINONI, Luiz Guilherme; MITIDIERO, Daniel. Curso de Direito Constitucional. 7. ed. São Paulo: Saraiva, 2018.

SARMENTO, Daniel. Direitos Fundamentais e Relações Privadas. Rio de Janeiro: Lumen Juris, 2004.

SANTOS, Dayana Brunetto Carlin dos. A biopolítica educacional e o governo de corpos transexuais e travestis. Cad. Pesqui. São Paulo, v. 45, n. 157, jul./set. 2015. Disponível em: http://www.scielo.br/scielo.php?script=sci_arttext\&pid=S010015742015000300630. Acesso em: 27 dez. 2019.

SINDICATO DOS TRABALHADORES NAS INDÚSTRIAS, MECÂNICAS E DE MATERIAL ELÉTRICO DE PE (SINDMETAL-PE). MEC homologa resolução que 
permite que transexuais e travestis usem o nome social nas escolas do Brasil. Disponível em: http://sindmetalpe.org.br/2018/01/18/post6421/. Acesso em: 07 jan. 2020.

SOUZA, Marilene Proença Rabello de; TEIXEIRA, Daniele Caetano da Silva; SILVA, Maria Carolina Yazbek Gonçalves. Conselho Tutelar: um novo instrumento social contra o fracasso escolar? Psicologia em Estudo. Maringá, v. 8, n. 2, pp. 71-82, 2003.

TAVARES, André Ramos. Curso de Direito Constitucional. 6 ed. São Paulo: Saraiva, 2008

Data da submissão: 05/11/2019

Data da primeira avaliação: $14 / 04 / 2020$

Data da segunda avaliação: 24/04/2020

Data da aprovação: $24 / 04 / 2020$ 